University of Wollongong

Research Online

Faculty of Engineering and Information

Faculty of Engineering and Information

Sciences - Papers: Part B

Sciences

2020

\title{
Equivalent static force method for selective storage racks with uplifting baseplates
}

James Maguire

University of Wollongong, jrm978@uowmail.edu.au

Lip H. Teh

University of Wollongong, Iteh@uow.edu.au

G Charles Clifton

University of Auckland

Timothy J. McCarthy

University of Wollongong, timmc@uow.edu.au

Follow this and additional works at: https://ro.uow.edu.au/eispapers1

Part of the Engineering Commons, and the Science and Technology Studies Commons

Research Online is the open access institutional repository for the University of Wollongong. For further information contact the UOW Library: research-pubs@uow.edu.au 


\title{
Equivalent static force method for selective storage racks with uplifting baseplates
}

\author{
Abstract \\ This paper is concerned with the equivalent static force method for the seismic design of selective \\ storage racks with uplifting baseplates. It proposes a new procedure for determining the effective natural \\ period of such racks in the cross-aisle direction for use in the NZS 1170.5 equivalent static method. The \\ procedure is derived by comparing the base shear results of trialled Rayleigh methods against nonlinear \\ time history analysis results involving 15 upright frame configurations, comprising 5 baseplate types for \\ three, five and seven level racks. The time history analyses use a suite of 44 ground motion records. It is \\ recommended that the effective natural period be computed in the Rayleigh method using nonlinear static \\ analysis with the storage loads included, where the Rayleigh lateral loads create an overturning moment \\ equal to the restoring moment of the storage loads. The proposed procedure leads to more efficient \\ designs of storage racks with uplifting baseplates compared to the conventional procedure based on the \\ use of linear analysis in the Rayleigh method for determining the natural period, but results in more \\ conservative designs compared to the use of nonlinear time history analysis.

\section{Disciplines} \\ Engineering | Science and Technology Studies

\section{Publication Details} \\ Maguire, J. R., Teh, L. H., Clifton, G. Charles. \& McCarthy, T. J. (2020). Equivalent static force method for \\ selective storage racks with uplifting baseplates. Journal of Constructional Steel Research, 165 \\ 105821-1-105821-9.
}




\title{
Equivalent static force method for selective storage racks with uplifting baseplates
}

\author{
James R. Maguire ${ }^{\mathrm{a}}$, Lip H. Teh ${ }^{\mathrm{a}}$, G. Charles Clifton ${ }^{\mathrm{b}}$, Timothy J. McCarthy ${ }^{\mathrm{a}}$

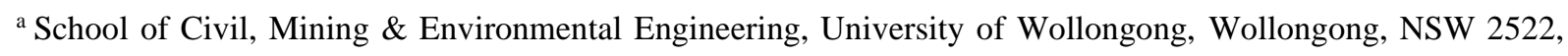 \\ Australia. \\ ${ }^{\mathrm{b}}$ Department of Civil and Environmental Engineering, University of Auckland, Auckland, New Zealand.
}

\section{Abstract}

This paper is concerned with the equivalent static force method for the seismic design of selective storage racks with uplifting baseplates. It proposes a new procedure for determining the effective natural period of such racks in the cross-aisle direction for use in the NZS 1170.5 equivalent static method. The procedure is derived by comparing the base shear results of trialled Rayleigh methods against nonlinear time history analysis results involving 15 upright frame configurations, comprising 5 baseplate types for three, five and seven level racks. The time history analyses use a suite of 44 ground motion records. It is recommended that the effective natural period be computed in the Rayleigh method using nonlinear static analysis with the storage loads included, where the Rayleigh lateral loads create an overturning moment equal to the restoring moment of the storage loads. The proposed procedure leads to more efficient designs of storage racks with uplifting baseplates compared to the conventional procedure based on the use of linear analysis in the Rayleigh method for determining the natural period, but results in more conservative designs compared to the use of nonlinear time history analysis.

Keywords: cold-formed steel storage racks; equivalent static force method; natural period; seismic design; rocking

\section{Introduction}

A cold-formed steel selective storage rack consists of a row of upright frames, linked together in the down-aisle direction with clip-in beams at each storage level, as shown in Figure 1. The upright frames are typically tall and narrow in the cross-aisle direction. Cross-aisle lateral loads can cause significant overturning moments, which are resisted by the pallet weight and the 

anchor bolts.

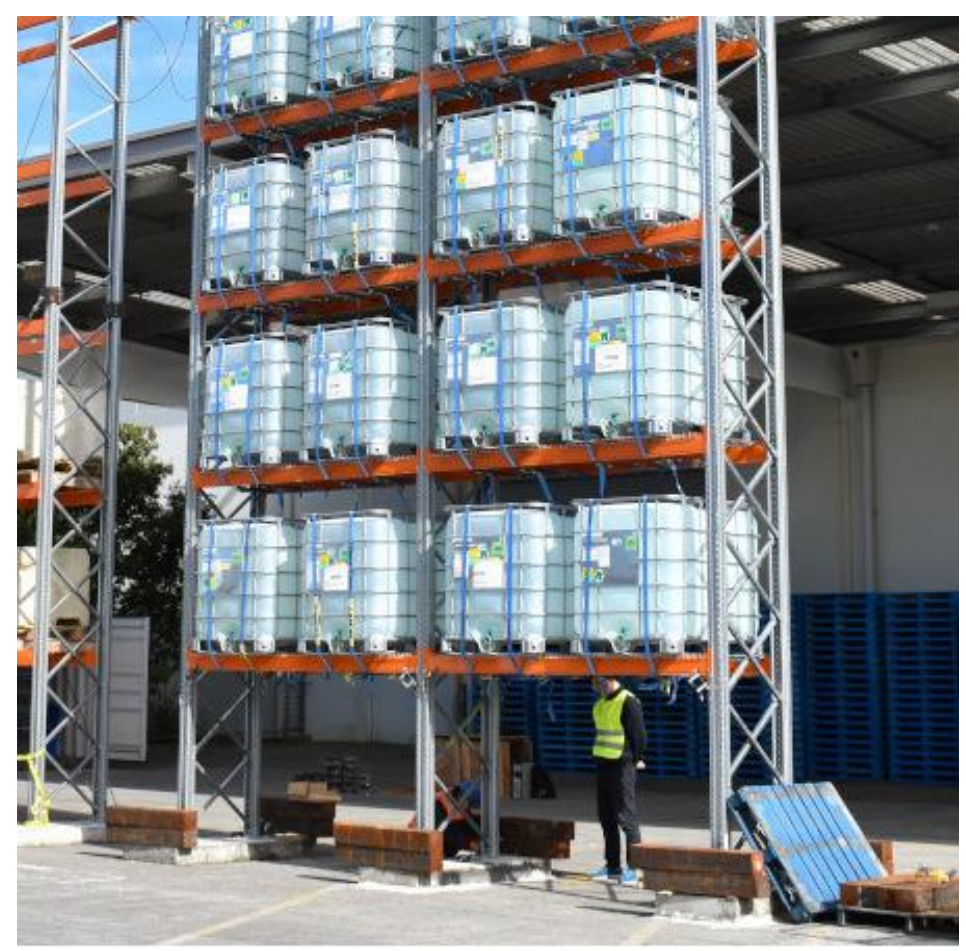

Figure 1: A selective storage rack

The design of selective storage racks in moderate to strong seismic regions presents some challenges to the structural engineer, especially one familiar with typical building seismic design. Standards for determining the seismic design loads are suited to buildings, but do not necessarily account for the unique characteristics of cold-formed steel storage racks. Design guidelines such as the BRANZ design guide (Beattie \& Deam 2006) suggest modifications to adapt the standards for use with storage racking. The BRANZ design guide, however, does not address some fundamental differences in structural behaviour between multi-storey buildings and cold-formed steel storage racks.

Racks are often anchored to the concrete slab using ductile baseplates or other mechanisms that allow uplift of the uprights under cross-aisle seismic loading. This uplift leads to the rack to rock in the cross-aisle direction, thus isolating the superstructure from seismic base shear. Although rocking behaviour and its effect can be modelled by the nonlinear time history analysis method, it requires significant investment of time, computing facilities and expertise. In practice, rack designers therefore use the equivalent static force method mandated by seismic design standards such as NZS 1170.5 (SNZ 2004). 
The use of rocking structural systems for bridge piers, shear walls and steel frames has become more common. In steel frames, similar to storage racks, it has been shown that a significant proportion of earthquake input energy can be dissipated by hysteresis damping from ductile uplifting baseplates and uplift of the frame centre of gravity (Azuhata, et al. 2005). More recently, rocking steel frame designs have been proposed that use post-tensioned cables to limit maximum displacements (Steele \& Wiebe 2016), replaceable fuses to provide additional energy dissipation (Hall, et al. 2010) or friction uplifting column bases (Freddi, et al. 2017). Well designed self-centring rocking braced frames have also been shown to achieve lower floor spectra than a similar buckling-restrained braced frame building (Pollino 2015).

Some limited research has been done on the application of rocking design to cold-formed steel storage racking. Quasi-static cyclic testing of a storage rack upright frame in the cross-aisle direction was used to demonstrate the energy dissipation capacity of ductile baseplates (Petrone et al. 2016). While rocking can amplify the upright compression force (Azuhata, et al. 2007; Priestley, et al. 1978), cold-formed steel uprights are able to remain undamaged after experiencing stomping forces $15 \%$ greater than their static compression capacities (Maguire et al. 2019).

Current seismic design standards that are applicable to storage racks include ANSI MH16.1:2012 (RMI 2012), EN 16681:2016 (ECS 2016) and NZS 1170.5:2004 (SNZ 2004). The design methods detailed in these standards include the equivalent static force method, the modal response spectrum method and the time history analysis method. Both the equivalent static force method and the modal response spectrum method do not take into account the stomping and uplift that occur during rocking. ANSI MH16.1:2012 does not consider rocking at all, while EN 16681:2016 only accounts for rocking of the pallet loads but not of the rack structure. NZ 1170.5:2004 requires a special study if rocking is to be used as an energy dissipation mechanism but gives no details of the procedure. Other seismic analysis methods of storage racks have been proposed including rigid-plastic analyses (Montuori et al. 2019).

In the equivalent static force method, the magnitudes of the horizontal loads are computed based on the (first) natural period of the structure. In design practice, the natural period is most commonly determined using the Rayleigh method (SNZ 2004, Bernuzzi et al. 2015). However, for a rocking rack, there are two fundamental problems in the application of the equivalent static force method. First, the rocking period is not the natural period of the structure before rocking. 
Second, the natural period computed from the Rayleigh method depends on the magnitude of the Rayleigh lateral loads applied to the structure subject to uplifting.

If the lateral loads assumed in the Rayleigh method do not cause uplift of the upright on the "windward" side, then the computed natural period is that of the structure that does not rock, and is therefore too short (conservative). It should be noted that the use of a linear analysis in the Rayleigh method invariably leads to such an outcome. On the other hand, if the assumed lateral loads are high enough to cause uplift (in a nonlinear analysis), then the computed natural period can be much longer, although it is unknown whether it would lead to an unsafe design.

The present study aims to derive a procedure for determining the effective natural period of a selective storage rack that is subject to rocking during earthquake, to be used in the equivalent static method prescribed in Section 6.2 of NZS 1170.5:2004 (SNZ 2004). For this purpose, 15 upright frame configurations comprising 5 baseplate types for three, five and seven level racks have been studied using nonlinear time history analyses under a suite of 44 ground motion records. The criterion for the new procedure is that it must lead to more efficient designs compared to the conventional procedure of using linear analysis in the Rayleigh method, but cannot underestimate the design forces obtained in the nonlinear time history analysis.

\section{Rack Configurations and Modelling}

\subsection{Upright frame}

Planar finite element models of selective rack upright frames in the cross-aisle direction were developed using the OpenSees software framework (McKenna 2016), as illustrated in Figure 2 for a three level rack. The upright frame model consists of elastic beam-column elements as upright members, and truss elements as bracing members. 


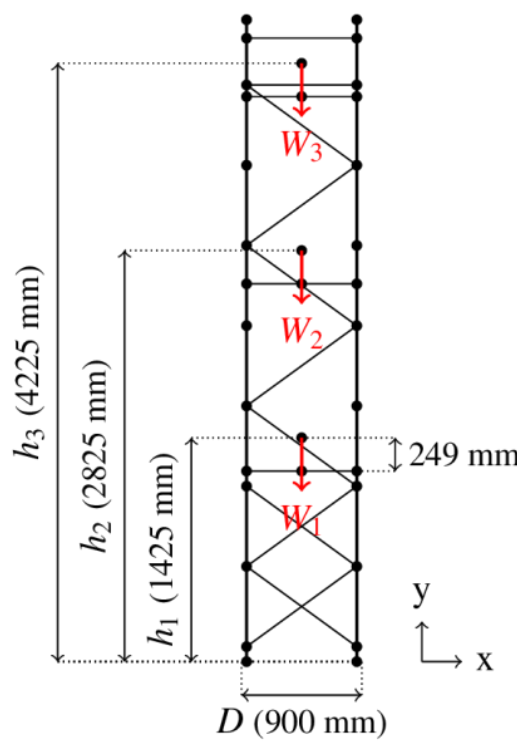

Figure 2: Finite element model of a three-level upright frame.

101 The upright nodes are vertically spaced at a distance equal to the bracing pitch $(600 \mathrm{~mm})$ with

102 a frame width of $900 \mathrm{~mm}$. Two pitches of X-bracing are provided, starting at the frame base,

103 with a K-bracing pattern above continuing to the top. Two horizontal braces are provided at the

104 top of the upright frame.

105 Additional upright nodes are placed at each beam level, with the first beam level at $1.425 \mathrm{~m}$ 106 and each subsequent level $1.4 \mathrm{~m}$ above the previous. At each beam level, a node is located in 107 the middle of the frame connected to a node at the pallet's centre of mass, $249 \mathrm{~mm}$ above the 108 beam level, by a rigid link element. The node at the pallet's centre of mass has a nodal mass in 109 the vertical and horizontal directions, equal to the mass of the pallet.

110 Steel material properties applied to the upright and bracing elements are: elastic modulus of $111200 \mathrm{GPa}$, shear modulus of $80 \mathrm{GPa}$, yield stress of $450 \mathrm{MPa}$ and density of $7850 \mathrm{~kg} / \mathrm{m}^{3}$. Three 112 sets of upright and bracing profiles were selected to match the respective pallet loads of the 113 three, five and seven level racks studied in the present work. The area and the second moment 114 of area (about the Z-axis as shown in Figure 2) of the upright and bracing sections are shown 115 in Table 1.

116 Clause 6.1.3.1 of NZS 1170.5:2004 (SNZ 2004) restricts the application of the equivalent static 117 method to regular structures with natural periods up to $2 \mathrm{~s}$, or up to $0.4 \mathrm{~s}$ for irregular structures, 118 unless the structure is not taller than $10 \mathrm{~m}$. The tallest model in this paper is $9.825 \mathrm{~m}$. 
Table 1: Section properties of upright and bracing elements

\begin{tabular}{ccccc}
\hline Element & Rack levels & $\begin{array}{c}\text { Area } \\
\left(\times 10^{-6} \mathrm{~m}^{2}\right)\end{array}$ & $\begin{array}{c}I_{z} \\
\left(\times 10^{-9} \mathrm{~m}^{4}\right)\end{array}$ & $\begin{array}{c}\text { Self mass } \\
(\mathrm{kg} / \mathrm{m})\end{array}$ \\
\hline \multirow{3}{*}{ Upright } & 3 & 474 & 152 & 3.72 \\
& 5 & 611 & 337 & 4.80 \\
& 7 & 1028 & 1237 & 8.07 \\
\hline \multirow{3}{*}{ Bracing } & 3 & 13.8 & - & 1.19 \\
& 5 & 23.0 & - & 1.98 \\
& 7 & 32.2 & - & 2.77 \\
\hline
\end{tabular}

\subsection{Baseplate Types}

123 The five baseplate types included in the present study are a standard ductile (SD), a heavy duty 124 (HD) and three linear spring (LS02, LS04, LS40) baseplates. The SD and HD baseplates correspond to Dexion 90 MD and Dexion 90 XHD baseplates, shown in Figure 3. The LS02,

126 LS04 and LS40 baseplates allow uplift in tension at a linear stiffness of 2, 4 and $40 \mathrm{kN} / \mathrm{mm}$,

127 respectively. The stiffness of the LS02 and LS04 baseplates were chosen as two intermediate 128 values between the effective stiffnesses of the SD and HD baseplates. The load-displacement 129 relationships of the SD and HD baseplates were determined by cyclic axial loading tests 130 (Maguire, et al. 2018).
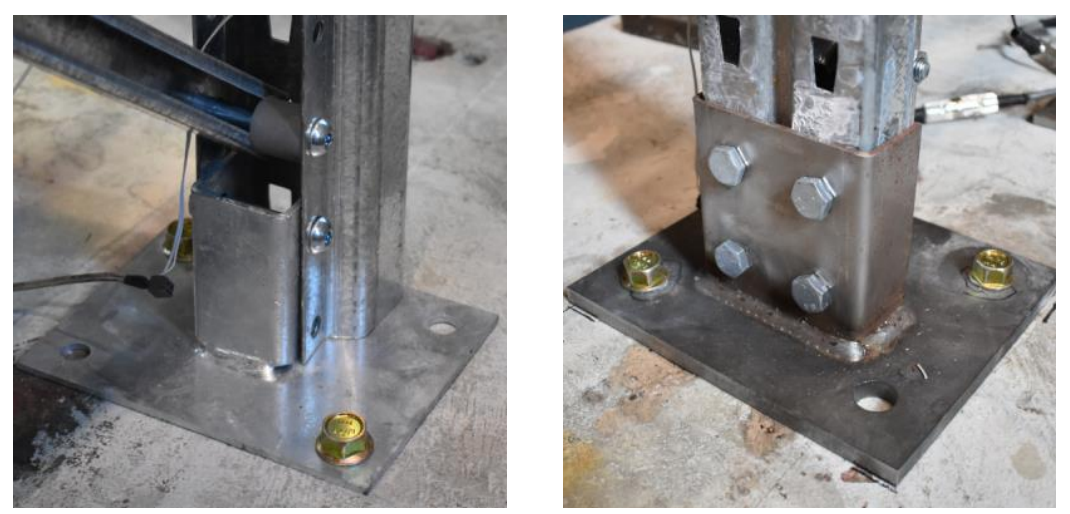

Figure 3: Standard ductile (left) and heavy duty (right) baseplates

132 In tension, the SD baseplate had an initial stiffness of $1.75 \mathrm{kN} / \mathrm{mm}$ up to an axial load of $1 \mathrm{kN}$, 133 where bolt slip began. The baseplate stub of the SD baseplate had a slotted bolt opening that

134 allowed about $3.5 \mathrm{~mm}$ of slip. The baseplate then continued to deform elastically at its initial 135 stiffness before yielding at $11 \mathrm{kN}$. After yielding, the baseplate plastically deformed as shown 136 in Figure 4. The SD baseplate can undergo large displacements, allowing a storage rack to rock. 


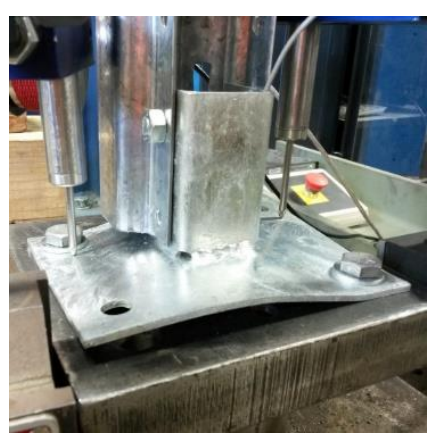

Figure 4: Ductile behaviour in tension of SD baseplate during cyclic axial testing.

138 The HD baseplate is significantly stiffer than the SD baseplate, with an elastic stiffness of

$13912.9 \mathrm{kN} / \mathrm{mm}$. The HD baseplate was connected to the upright web with four bolts as shown in

140 Figure 3, resulting in a shorter bolt slip of $2.5 \mathrm{~mm}$ at an axial tension of $1.5 \mathrm{kN}$.

\section{$141 \quad 2.3 \quad$ Baseplate modelling}

142 Each baseplate was modelled as a zero-length element connecting the node at the base of the 143 upright to a vertically restrained 'floor node' at the same location. The five baseplate types were 144 differentiated by the response models applied to the zero-length element in the vertical axis, 145 shown in Figure 5. All baseplates have a stiffness in compression of $40 \mathrm{kN} / \mathrm{mm}$, which 146 approximates the stiffness of the concrete slab as found from the experimental tests.

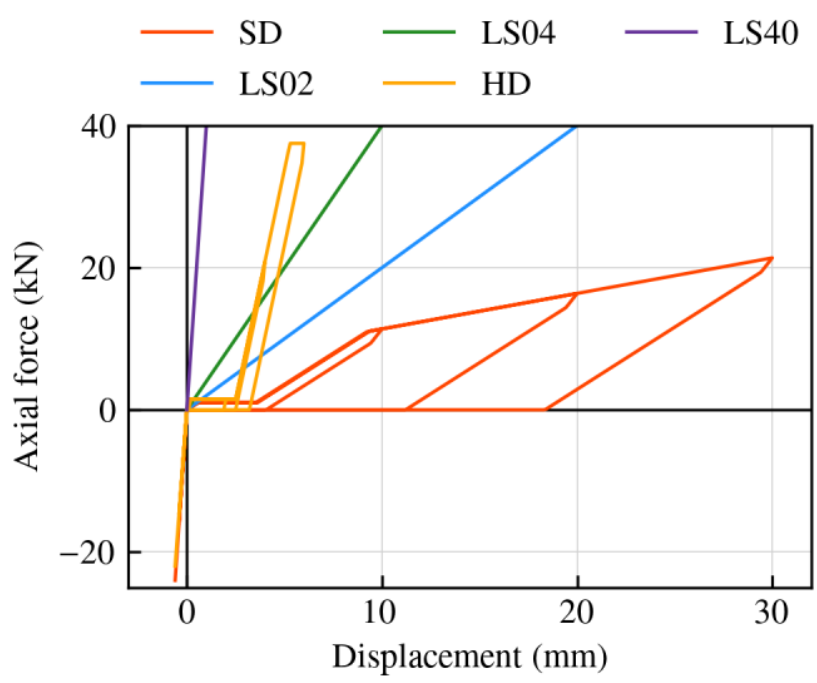

Figure 5: Baseplate response models

148 The SD and HD models were built using elastic perfectly-plastic gap materials in parallel to

149 simulate the bolt-slip behaviour. The HD baseplate model used an elastic multi-linear material in addition to the gap materials. 
151 Frame rocking was achieved in the model by applying the boundary conditions shown in Figure 1526 to the floor nodes. The floor node on the left hand side was restrained in all DOFs while that 153 on the right hand side was restrained in the vertical and rotational DOFs. The floor node on the 154 right hand side was free to move in the horizontal direction to allow for rotation of the structure 155 during uplift, shown in Figure 7. In Figure 6, the zero-length elements are shown to have a finite 156 length only to illustrate the existence of the floor and upright base nodes.

- Upright node

- Floor node

- Zero-length element

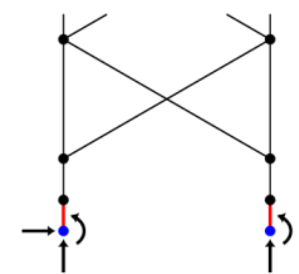

Figure 6: Baseplate model constraints

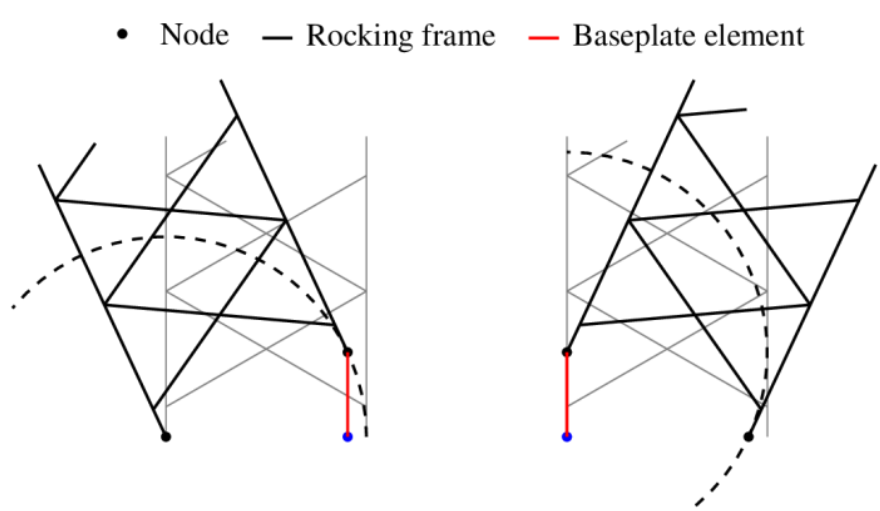

Figure 7: Baseplate model uplift behaviour

\subsection{Model validation}

161 The finite element methodology was validated against full-scale shaking table tests of a three-

162 level, two bay selective rack shown in Figure 8, using time history analyses. The rack was

163 loaded with six $800 \mathrm{~kg}$ pallets with a centre of gravity at $249 \mathrm{~mm}$ above the beam level. The 164 pallets were clamped onto the rack beams to prevent sliding and pallet shedding. Suitable 165 baseplate connection conditions were achieved by fixing three $40 \mathrm{MPa}$ reinforced concrete 166 blocks to the shaking table with post-tensioned bars and anchoring the baseplates to the concrete 167 blocks with two $75 \times 12 \mathrm{~mm}$ concrete screw anchors. 

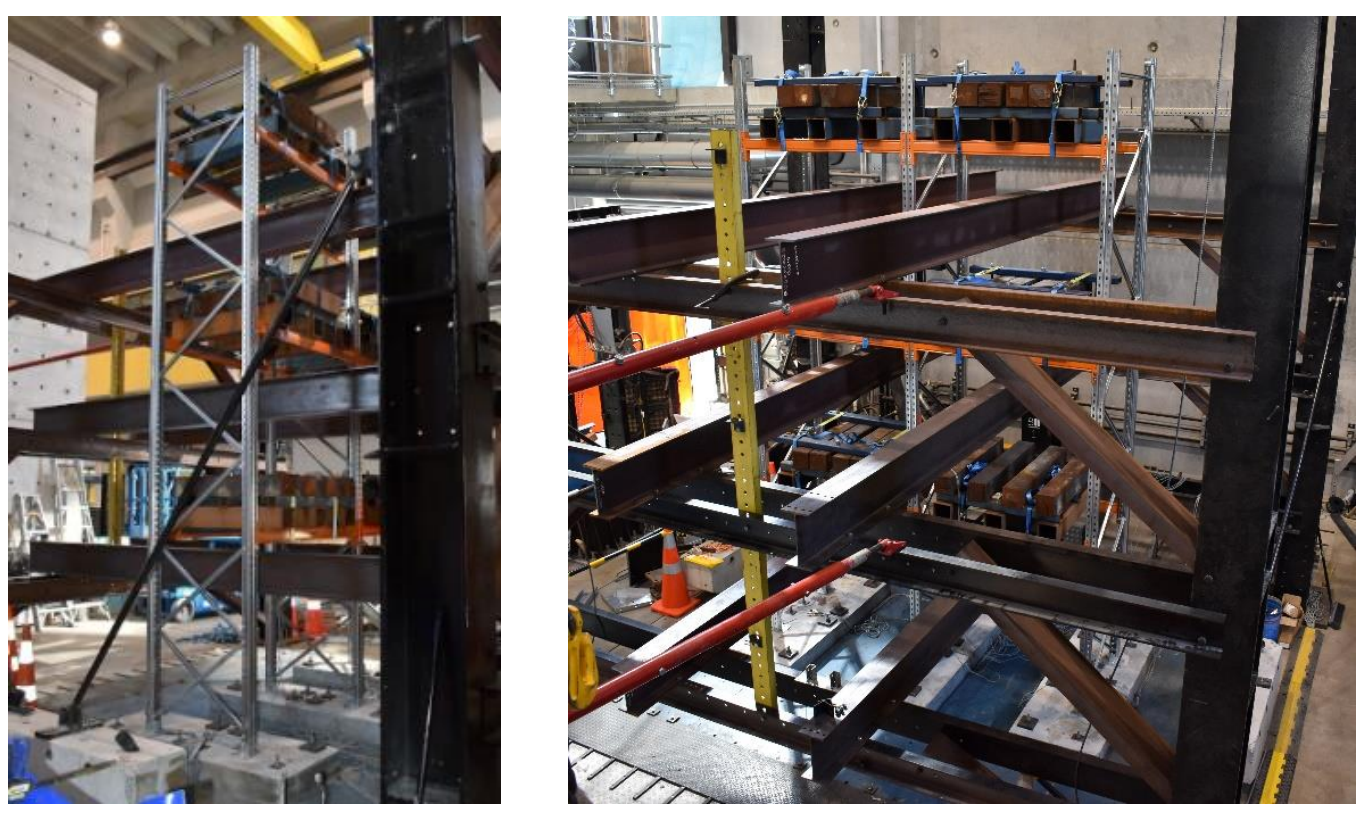

Figure 8: Shaking table test setup

169 The experiment showed that half of the structure weight was carried by the central upright

170 frame, with the two outer frames carrying a quarter of the structure weight each. The finite

171 element model represents the central upright frame in the experiment.

172 The cross-aisle displacement at the central upright frame was measured using a wire transducer

173 mounted on a rigid frame and connected to the upright just above the upright-to-beam

174 connection of the top level. Comparisons of the experimental and the time history analysis

175 results for the rack with the SD baseplate under the Kobe 1995 and Northridge 1994 ground

176 motions are shown in Figure 9. The finite element results match the experimental results

177 reasonably well. 


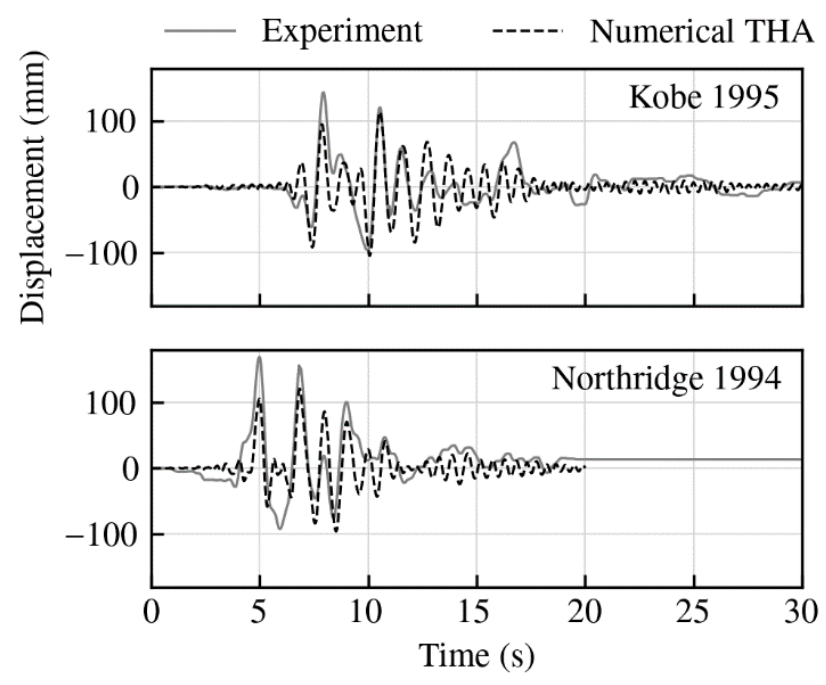

Figure 9: Validation of finite element model

\section{Analysis Procedures}

180 The present study consisted of two stages. The first stage aimed to derive a Rayleigh method 181 based procedure for determining the effective natural period of a rocking rack to be used in the equivalent static method specified in Clause 6.2 of NZS 1170.5:2004 (SNZ 2004). The effective natural period should result in a design base shear comparable to the mean base shear obtained in the nonlinear time history analyses under a suite of 44 ground motion records.

The second stage compared the maximum compression forces of the uprights between the nonlinear time history analyses and the equivalent static force method using the effective natural period.

In all analyses, full gravity loading was applied in advance and P-delta effects were taken into account. Gravity loading was applied to the nodes at the centre of gravity of each pallet weighing $7.85 \mathrm{kN}$. The self-weight of each frame member was applied at the member's centre of gravity.

For the purpose of determining the site hazard spectrum, a hypothetical site in Wellington with subsoil class $\mathrm{C}$ was chosen. A return period factor of 1.0 and distance of $4 \mathrm{~km}$ to the nearest

194 major fault was assumed. Ductility factor $\mu=1.0$ was used as nonlinear material properties were accounted for in the baseplate models. 


\subsection{First stage}

197 Each upright frame model was subjected to a series of Rayleigh analyses to determine the

198 natural period, beginning with a total Rayleigh lateral load $R$ of $1 \mathrm{kN}$ at increments of $0.5 \mathrm{kN}$ 199 until overturning failure in the nonlinear static analysis. Each Rayleigh lateral load $R$ was 200 distributed over the height of the frame in the same manner as the seismic base shear in 201 accordance with Clause 4.6 of the BRANZ Design Guide (Beattie \& Uma 2012):

$$
R_{i}=R \frac{W_{i} h_{i}}{\sum_{i=1}^{n}\left(W_{i} h_{i}\right)}
$$

202

203

204

205 location.

206

For each Rayleigh analysis, the (first) natural period of vibration $T_{1}$ was computed from

$$
T_{1}=2 \pi \sqrt{\frac{\sum_{i=1}^{n}\left(W_{i} d_{i}^{2}\right)}{g \sum_{i=1}^{n}\left(R_{i} d_{i}\right)}}
$$

207 where $g$ is the gravity acceleration and $d_{i}$ is the horizontal displacement at level $i$.

208 Using the period $T_{1}$, the design base shear $V_{E S M}$ (SNZ 2004) was determined using:

$$
V_{E S M}=C\left(T_{1}\right) \frac{S_{p}}{k_{\mu}} \sum_{i=1}^{n} W_{i}
$$

209 where $C\left(T_{1}\right)$ is the elastic site hazard spectrum, shown in Figure 10, which is the product of the 210 hazard factor $(Z=0.4)$, return period factor $(R=1.0)$, near-fault factor, and the spectral shape 211 factor. Since $\mu=1, S_{p}=1$ and $k_{\mu}=1$ according to Clauses 4.4.2 and 5.2.1. 


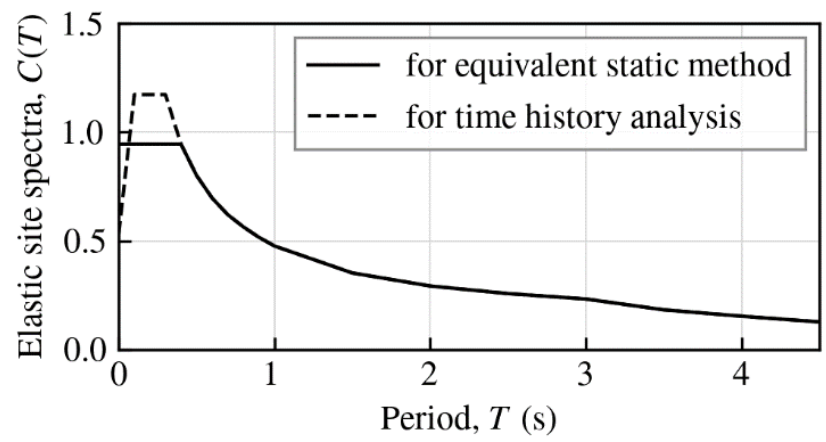

Figure 10: Elastic site hazard spectrum $C(T)$ for site subsoil class $C$ (shallow soil)

214 Nonlinear time history analyses were carried out using a suite of 44 ground motion records with 215 the period $T_{1}$ computed using Eqn (2). The ground motions were selected from the ATC-63 216 Far-Field Record suite developed for FEMA P695 (Applied Technology Council 2009). Each 217 ground motion record was scaled to the target spectrum:

$$
S A_{\text {target }}=\frac{1+S_{p}}{2} C\left(T_{1}\right)
$$

218 The scaling factor $k_{1}$ for each motion was determined by minimising the least square sum of $219 \log \left(k_{1} S A / S A_{\text {target }}\right)$ where $S A$ is the $5 \%$ damped ground motion spectra. For ground motions 220 that result in a scaling factor between 0.33 and 3.0, time history analysis using the scaled ground 221 motion was carried out to determine the peak base shear, $V_{T H A}$. Ground motions falling outside 222 of the range between 0.33 and 3.0 were not used as recommended by NZS 1170.5 (SNZ 2004).

223 Each time history analysis was conducted with a time step of $0.01 \mathrm{~s}$. If the analysis failed to 224 converge for a given time step, the time step was reduced to $0.005 \mathrm{~s}$ for the next $2.0 \mathrm{~s}$, and then 225 reset to the default $0.01 \mathrm{~s}$.

226 The effective natural period is the period which, when used in Eqn (3), leads to a design base shear $V_{E S M}$ that is representative of the median base shear obtained in the nonlinear time history analyses under the 44 ground motion records. Since the NZS 1170.5 (SNZ 2004) time history analysis procedure only requires the selection of three ground motions, the median base shear obtained over the 44 ground motion suite remains conservative. The derivation of the Rayleigh

231 based procedure for determining the effective natural period is detailed in Section 4. 


\subsection{Second stage}

233 In the second stage, the effective natural period of each upright frame model determined in the 234 first stage was used to conduct the equivalent static method in accordance with Clause 6.2 of 235 NZS 1170.5:2004 (SNZ 2004), using linear static analysis. The design base shear $V_{E S M}$ was 236 distributed over the height of the frame in accordance with Clause 4.6 of the BRANZ Design 237 Guide (Beattie \& Uma 2012):

$$
F_{i}=V_{E S M} \frac{W_{i} h_{i}}{\sum_{i=1}^{n}\left(W_{i} h_{i}\right)}
$$

238 where $F_{i}$ is the equivalent static force applied at level $i$.

\section{9 \\ 4 Determination of the effective natural period}

\subsection{The computed natural periods of vibration}

241 The computed natural periods of vibration of the frames with uplifting baseplates, determined 242 by the Rayleigh method as expressed by Eqn (2), were found to be significantly affected by the 243 magnitude of the Rayleigh lateral loads applied, as shown in Figure 11 for the three-level 244 upright frames. For low lateral loads that do not cause uplift, all the frames with uplifting 245 baseplates have the same natural period of approximately $0.4 \mathrm{~s}$.

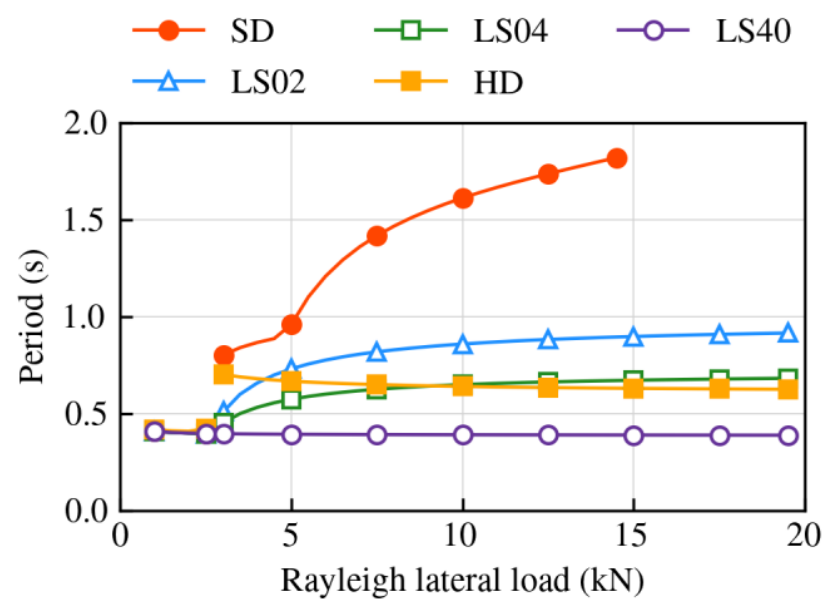

246 Figure 11: Natural periods of three-level upright frames as determined by the Rayleigh method.

247 When the lateral load is large enough to produce uplift, the computed natural period begins to 248 lengthen with increasing lateral load. The point at which uplift occurs can be determined by 
equating the overturning moment caused by the lateral load with the restoring moment of the 250 pallet weights:

$$
\frac{1}{2} D \sum_{i=1}^{n}\left(W_{i}\right)=\sum_{i=1}^{n}\left(R_{i} h_{i}\right)
$$

251 where $D$ is the frame depth as defined in Figure 2. For the load distribution described by Eqn 252 (1), the uplift threshold can be determined by:

$$
R_{\text {uplift }}=\frac{1}{2} D \sum_{i=1}^{n}\left(W_{i}\right) \frac{\sum_{i=1}^{n}\left(W_{i} h_{i}\right)}{\sum_{i=1}^{n}\left(W_{i} h_{i}^{2}\right)}
$$

253 If the pallet weight at each level is constant:

$$
R_{\text {uplift }}=\frac{1}{2} D W_{t} \frac{\sum_{i=1}^{n}\left(h_{i}\right)}{\sum_{i=1}^{n}\left(h_{i}^{2}\right)}
$$

254 For the three rack heights considered in this study, the threshold Rayleigh lateral load is given 255 in Table 2.

256 Table 2: Uplift thresholds

\begin{tabular}{ccc}
\hline $\begin{array}{c}\text { Number of } \\
\text { levels }\end{array}$ & $\begin{array}{c}\text { Level heights, } h_{i} \\
(\mathrm{~m})\end{array}$ & $\begin{array}{c}\text { Uplift threshold, } R_{\text {uplift }} \\
(\mathrm{kN})\end{array}$ \\
\hline 3 & $1.425,2.825,4.225$ & 3.03 \\
5 & $\ldots, 5.625,7.025$ & 3.30 \\
7 & $\ldots, 8.425,9.825$ & 3.43 \\
\hline
\end{tabular}

258 At Rayleigh lateral loads greater than the uplift threshold, the computed natural periods of the 259 LS02 and LS04 baseplates lengthen at a high rate initially, but asymptote towards $0.92 \mathrm{~s}$ and $2600.68 \mathrm{~s}$, respectively. The SD and HD baseplates have higher rates of lengthening of the natural 261 period at the uplift threshold due to initial bolt slip. At higher Rayleigh lateral loads, the HD 262 baseplate's computed natural period shortens due to its high stiffness, while the SD baseplate's 263 period continues to lengthen due to its softening response as exhibited in Figure 6.

264 It is evident that the natural period of a frame with an uplifting baseplate, computed using the 265 Rayleigh method, is not unique but is a function of the magnitude of the Rayleigh lateral load 266 applied to the frame. 
As the stiffness in compression and tension is constant for the LS40 baseplate, the natural

268 periods of the frames having these baseplates are not affected by the magnitude of the Rayleigh lateral loads. For frames having these baseplates, the natural period can be determined by the conventional linear elastic analysis. For the nonlinear baseplate models, the increase in period

271 after uplift is influenced by the storage load and therefore cannot be determined by linear elastic 272 analysis.

\subsection{Design base shear}

274 The design base shears for a three-level rack with SD baseplate, determined using the equivalent 275 static method (ESM) of Clause 6.2 of NZS 1170.5:2004 (SNZ 2004) and those from the time 276 history analysis (THA), are shown in Figure 12. At the shorter assumed natural periods of $0.41 \mathrm{~s}$ 277 and $0.40 \mathrm{~s}$ (corresponding to Rayleigh lateral loads of $1.0 \mathrm{kN}$ and $2.5 \mathrm{kN}$, respectively), the 278 equivalent static method is conservative compared to the time history analysis. It should be 279 noted that the natural period should remain constant before the uplift threshold, but small 280 variations arise due to the Rayleigh method only approximating the true period. As the assumed 281 natural period increases from $0.80 \mathrm{~s}$ to $1.42 \mathrm{~s}$, the equivalent static method's design base shear 282 decreases and better matches the median base shear given by the time history analyses. The 283 equivalent static method becomes unconservative as the assumed natural periods increase 284 beyond $1.42 \mathrm{~s}$.

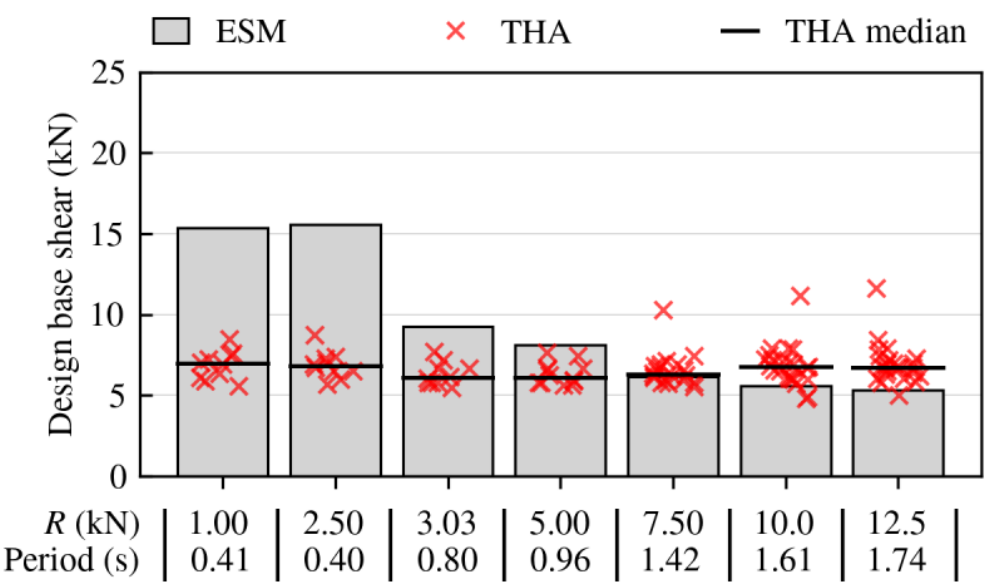

Figure 12: Design base shears for period values determined using increasing Rayleigh lateral loads for a three-level rack with SD baseplates.

287 Selection of the period of vibration $T_{1}$ has a significant effect of the design base shear in the 288 equivalent static method, due to the shape of the elastic site spectrum, which decreases for 
longer periods such that a structure with a $0.4 \mathrm{~s}$ natural period has a design base shear nearly

29010 times that of a structure with a $4.0 \mathrm{~s}$ natural period.

291 For time history analysis, the period selection has a smaller effect on the resulting base shear of the structure since the selection only influences the ground motion scale factor $k_{1}$. The ground motion is scaled by fitting its spectra to the target spectrum over the period range of $2940.4 T_{1}$ to $1.3 T_{1}$. Given that the shapes of the ground motion spectra are typically similar to the 295 target spectrum, time history analysis is less sensitive to the selected period of vibration than 296 the equivalent static method.

297 However, several ground motion records used in the present study were found to result in scale 298 factors that were sensitive to the assumed natural period $T_{1}$. For example, the three outliers seen 299 in Figure 12 for the periods of $1.42 \mathrm{~s}, 1.61 \mathrm{~s}$ and $1.74 \mathrm{~s}$ came from the ATC63 121021 ground 300 motion, shown in Figure 13. The ATC63 121021 record produced a low response for periods 301 above $1 \mathrm{~s}$, resulting in an $80 \%$ increase in scale factor when using a $T_{1}$ of $2.21 \mathrm{~s}$, compared to 302 a $T_{1}$ of $1.32 \mathrm{~s}$.

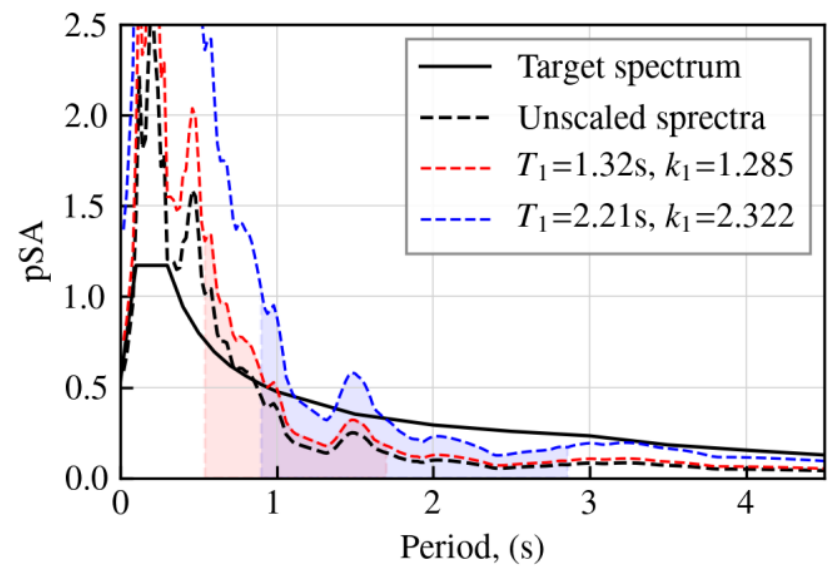

303 304

Figure 13: Spectra for the ATC63 121021 ground motion (Loma Prieta, 1989), with the scaling range of $0.4 T_{1}$ to $1.3 T_{1}$ highlighted.

For the three-level rack having the LS02 and LS04 baseplates, which are linearly elastic in tension, the base shear values of the equivalent static method and the time history analysis method agreed well with each other as higher natural periods were assumed, as evident in Figure 14 for the rack with LS02 baseplates. However, as with the rack with SD baseplates discussed previously, the equivalent static method based on the lower natural periods led to overestimation of the design base shear. 


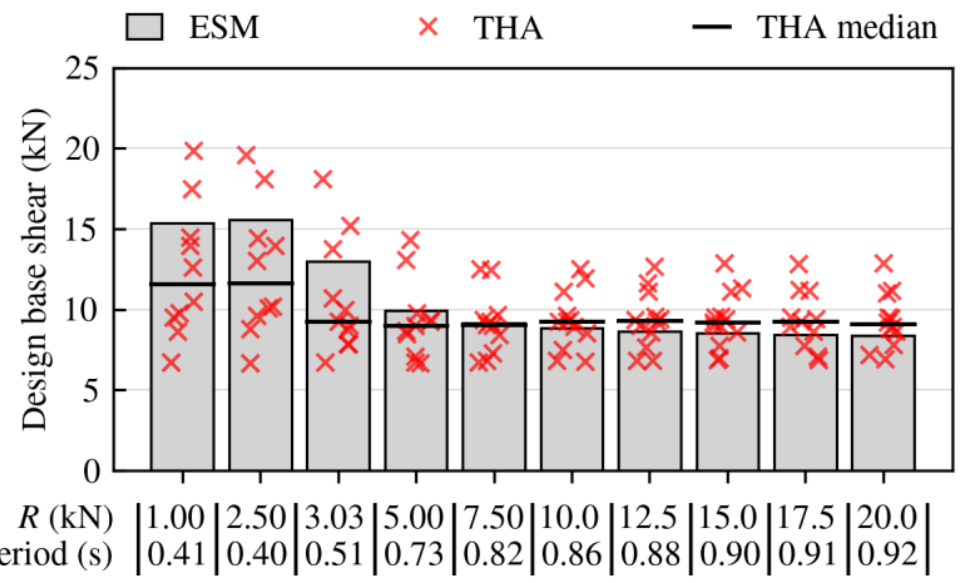

311 Figure 14: Design base shears for period values determined using increasing Rayleigh lateral loads for a three-level rack with LS02 baseplates.

313 The equivalent static method and the time history analysis method happened to produce 314 consistent base shears across a large range of Rayleigh lateral loads for the racks with HD baseplates, as shown in Figure 15 for a three-level rack.

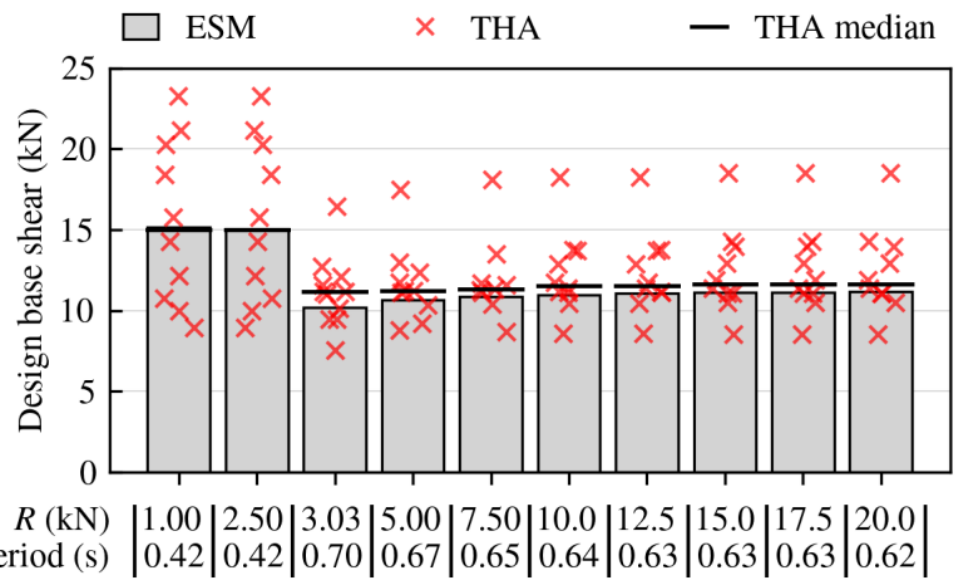

316 Figure 15: Design base shears for period values determined using increasing Rayleigh lateral loads for a three-level rack with HD baseplates.

318 The ratios of the design base shear $V_{E S M}$ determined by the equivalent static method to the median base shear obtained by the time history analyses are summarised for all racks in Figure 16. The figure shows that the optimal periods for the equivalent static method correspond to

321 Rayleigh lateral loads somewhere between the uplift thresholds and $7.5 \mathrm{kN}$. For taller racks, the optimal period tends to correspond to the uplift threshold. 

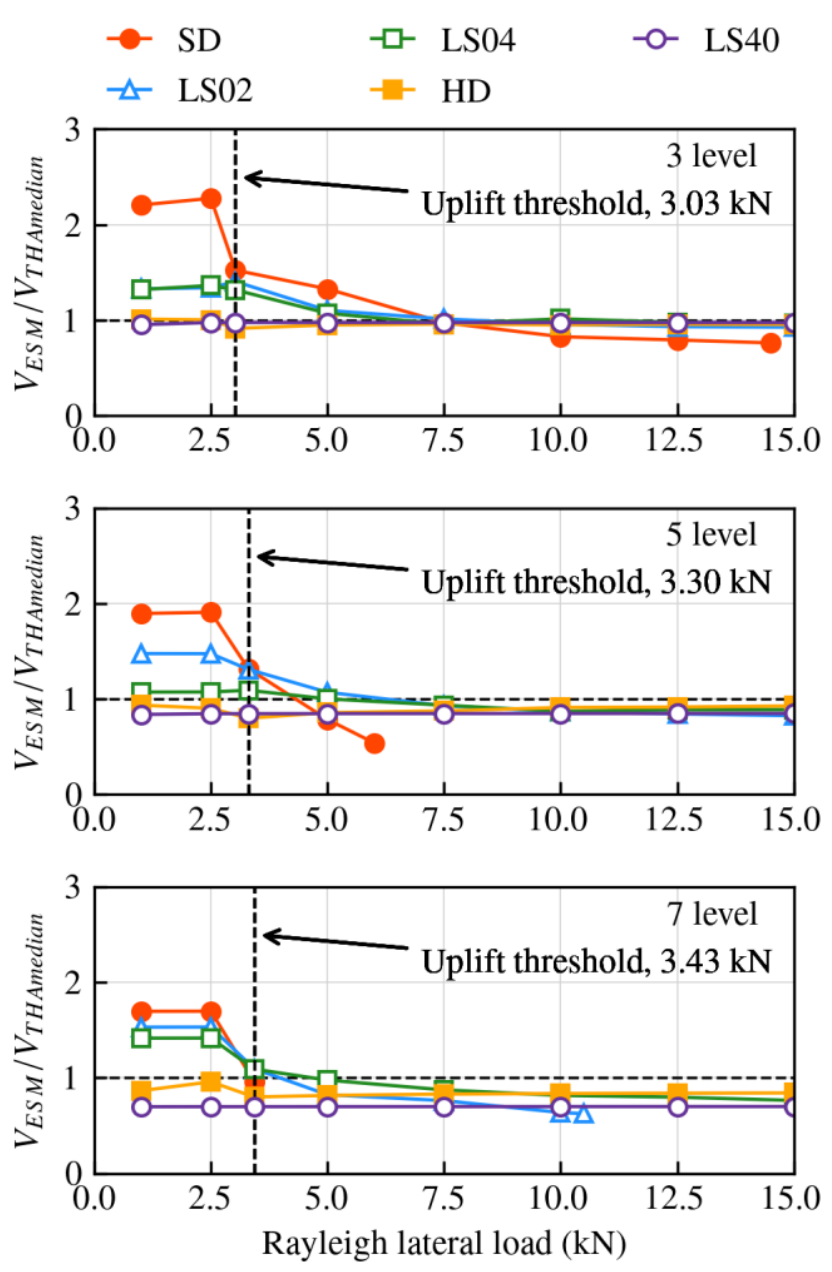

Figure 16: Accuracy of the assumed natural periods based on the Rayleigh method

324 For practical purposes, using the natural period computed based on the Rayleigh lateral loads 325 corresponding to the uplift threshold appears to be reasonable, and is therefore proposed in this paper. Figure 16 shows that such an equivalent static method gives design base shears that are more efficient with respect to the time history analysis than those based on the conventional Rayleigh method, yet mostly conservative.

329 The racks with LS40 baseplates have a constant natural period, and therefore were not affected 330 by the period selection. There was a good match between the equivalent static method and the 331 time history analysis for the three-level rack with LS40 baseplates, but the equivalent static 332 method gave lower base shear as the rack increased in height. However, the underestimation of 333 the design base shear does not necessarily mean same of the upright compression forces, as 334 shown in the next section. 


\section{Implications of the proposed procedure}

336 This section investigates the implications of the procedure proposed in the preceding section

337 for determining the effective natural period of a rack with uplifting baseplates. It should be

338 noted that an underestimation of the design base shear in the equivalent static force method

339 does not necessarily lead to underestimation of the upright design force. During ground motion

340 (time history analysis), the peak upright force may not coincide with the peak base shear. The

341 ratios of the design upright compressive force in the equivalent static method to the median

342 peak upright force in the time history analyses are shown in Figure 17.
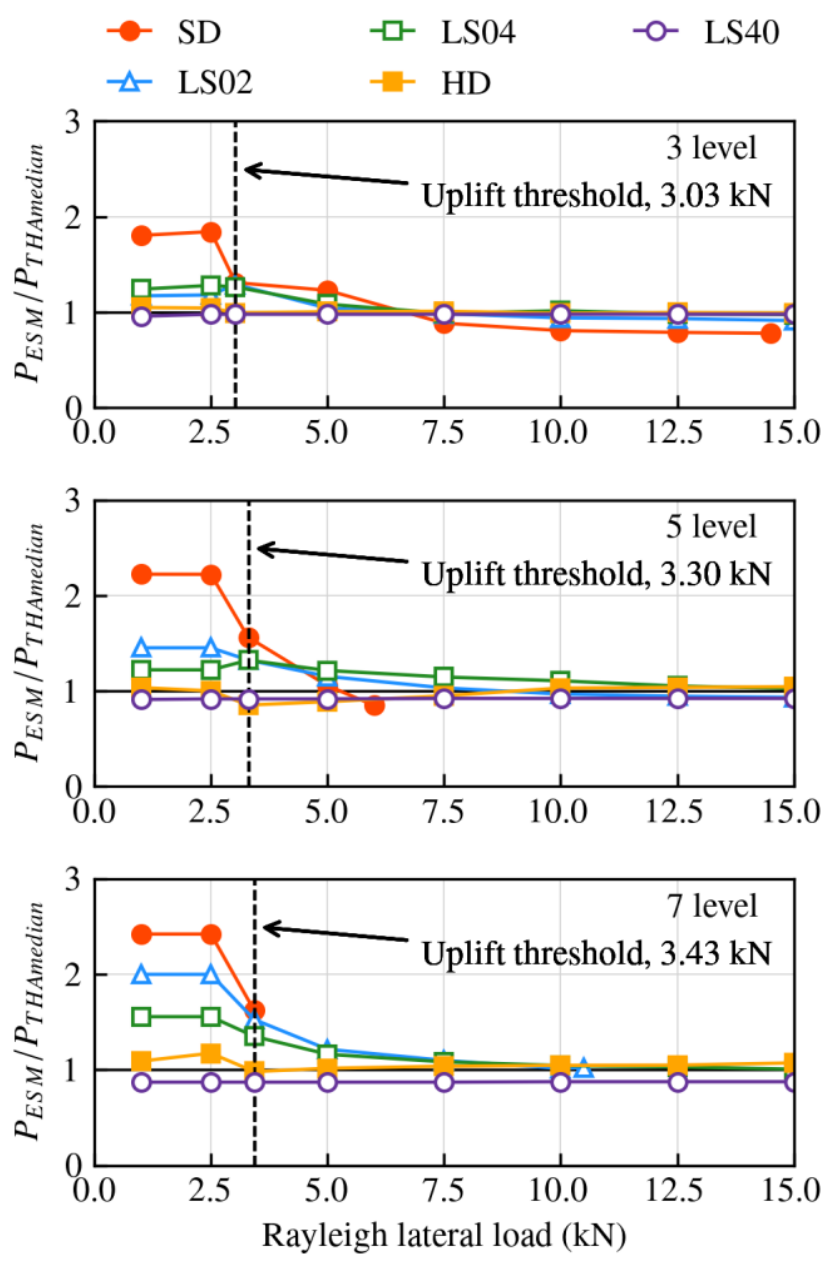

Figure 17: Ratio of ESM's design upright axial load to THA's median peak upright axial load.

344 The upright design force given by the equivalent static method $P_{E S M}$ tends to approach the time 345 history analysis median value as the Rayleigh lateral load used to determine the period of 346 vibration increases. At low Rayleigh lateral loads for all rack heights, the baseplate design force $347 P_{E S M}$ is overestimated by the equivalent static method by up to $240 \%$ for the more flexible 
348 baseplate types (SD, LS02 and LS04), while the stiff baseplates (HD and LS40) remain mostly 349 constant.

350 In any case, it can be concluded that determining the effective natural period of vibration at the 351 uplift threshold is significantly more accurate than the conventional Rayleigh method based on 352 linear analysis.

\section{Additional verifications}

\section{$354 \quad$ 6.1 Pallet mass}

355 An additional suite of simulations was conducted on the three-level rack with double the pallet 356 load (1600 kg per level). As seen in Figure 18, the base shear obtained using the Rayleigh lateral 357 loads at the uplift threshold is reasonable for the SD, LS02 and LS04 baseplates. For the racks 358 with HD or LS40 baseplates, the equivalent static method's base shears $V_{E S M}$ are 359 unconservative regardless of the Rayleigh lateral loads. In general, the proposed procedure is 360 more accurate than the conventional Rayleigh method.

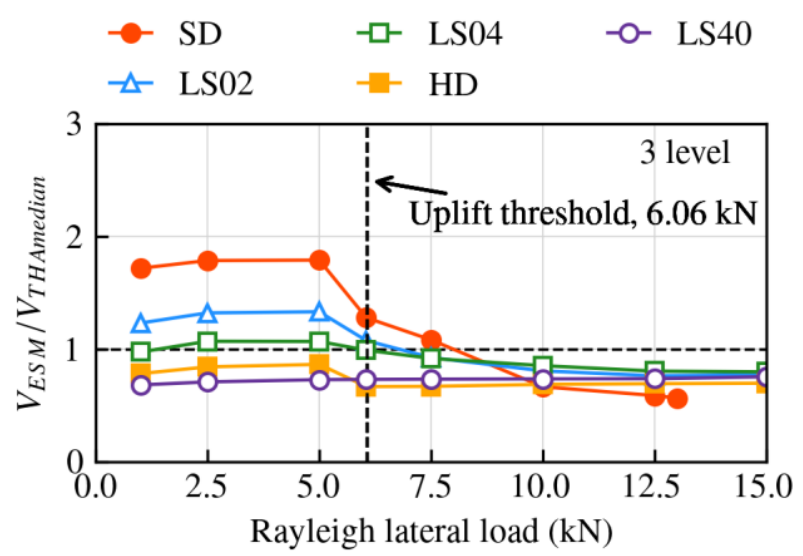

361 Figure 18: Ratio of ESM's base shear to THA's median peak base shear with $1600 \mathrm{~kg}$ pallet loads.

\subsection{Baseplate compression stiffness}

364 As mentioned in Section 2.3, the baseplate stiffness in compression used for the rack models in 365 Section 4 was $40 \mathrm{kN} / \mathrm{mm}$, based on the experimental test results. In order to assess the 366 sensitivity of the analysis results to the baseplate compression stiffness, another suite of 367 simulations on the three-level rack was conducted with a stiffness of $400 \mathrm{kN} / \mathrm{mm}$. The results 
plotted in Figure 19 show that using the Rayleigh lateral load corresponding to the uplift 369 threshold is still reasonable.

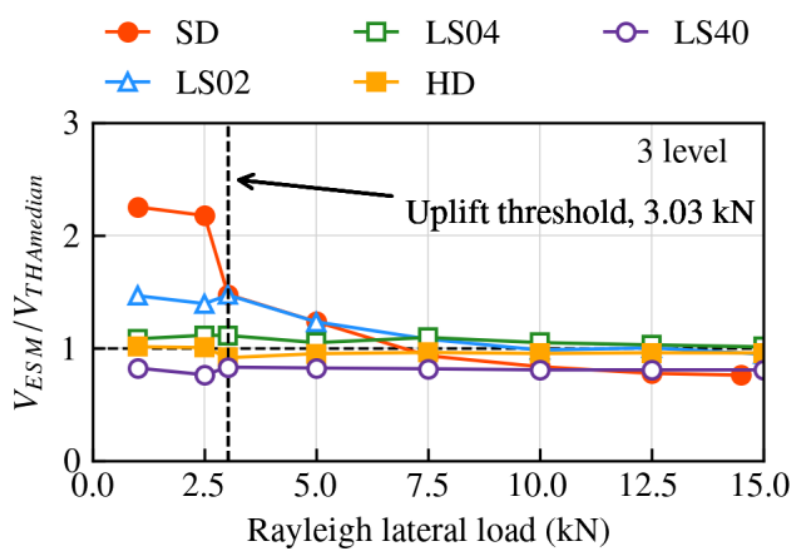

370

371

372

373

374

375

376

377

378

379

380

381

382

383

384

385

386

387

388
Figure 19: Ratio of ESM's base shear to THA's median peak base shear with baseplate compressive stiffness of $400 \mathrm{kN} / \mathrm{mm}$.

\section{Conclusions}

This paper has presented a comparison of the equivalent static method and the nonlinear time history analysis method, both as prescribed in NZS 1170.5:2004, as applied to the seismic structural analysis of selective storage racks in the cross-aisle direction. The racks had baseplates that were subject to uplift and rocking during earthquake, and therefore did not actually have constant natural periods of vibration, which are required to determine the equivalent static forces. A further complicating factor is that, according to NZS 1170.5:2004, the ground motion record used in the time history analysis method should be scaled based on the natural period of the structure.

It was found that using the natural period of vibration determined based on linear analysis in the Rayleigh method results in significant over-estimations of the equivalent static forces for racks with standard uplifting baseplates, preventing the benefits of using uplifting baseplates from being realised in the design. Based on the comparison of the base shear results between the time history analysis method and the trialled Rayleigh methods, it is proposed that the effective natural period of vibration be determined in the Rayleigh method using nonlinear static analysis, and be computed for the Rayleigh lateral loads that just result in uplift of the baseplate. 
The proposed method for determining the effective natural period leads to storage racks with uplifting baseplates that are more efficient than the conventional method of using linear analysis in the Rayleigh method, but tends to be more conservative than the time history analysis method.

\section{Acknowledgements}

This research has been conducted with the support of the Australian Government Research Training Program Scholarship and QuakeCoRE, a New Zealand Tertiary Education Commission-funded Centre. The authors would like to thank James Lim and Zhenghao Tang for their contributions to the shaking table test program, the results of which are used in this paper. Storage racking materials were donated for testing by Dexion New Zealand Ltd.

\section{References}

Applied Technology Council. 2009. "Quantification of Building Seismic Performance Factors - FEMA P695.” Federal Emergency Management Agency.

Azuhata, T., T. Ishihara, and M. Midorikawa. 2007. "Effect of Impulsive Force on Earthquake Response of Rocking Structural Systems.” In WIT Transactions on the Built Environment, I:459-68. WIT Press.

Azuhata, T., M. Midorikawa, and T. Ishihara. 2005. "The Seismic Energy Dissipation Mechanism of Rocking Structural Systems with Yielding Base Plates.” Earthquake Resistant Engineering Structures V, WIT transactions on the built environment, 81: 12.

Beattie, G. J., and B. L. Deam. 2006. Seismic Design of High Level Selective Storage Racking Systems with Public Access. BRANZ Design Guide. Judgeford, New Zealand: BRANZ Ltd. Beattie, G. J., and S. R. Uma. 2012. "Seismic Design of High Level Selective Storage Racking Systems and Racks with Public Access.” BRANZ Design Guide. BRANZ Ltd.

Bernuzzi, C., Gobetti, A., Gabbianelli, G., and Simoncelli, M. (2015) "Simplified Approaches to Design Medium-Rise Unbraced Steel Storage Pallet Racks. II: Fundamental Period Estimates.” Journal of Structural Engineering, 141 (11), 04015037.

European Committee for Standardization. 2016. "Steel Static Storage Systems - Adjustable Pallet Racking Systems - Principles for Seismic Design, En 16681:2016.” Standard. CEN.

Freddi, F., C.A. Dimopoulos, and T.L. Karavasilis. 2017. "Rocking Damage-Free Steel Column Base with Friction Devices: Design Procedure and Numerical Evaluation." Earthquake Engineering \& Structural Dynamics, 46 (14): 2281-2300. 
Hall, K.S., M.R. Eatherton, and J.F. Hajjar. 2010. "Nonlinear Behavior of Controlled Rocking Steel-Framed Building Systems with Replaceable Energy Dissipating Fuses, NSEL Report 026." Department of Civil; Environmental Engineering, University of Illinois at UrbanaChampaign.

Maguire, J.R., Teh L.H., Clifton G.C., and Lim J. B.P.. 2019. "Residual Capacity of ColdFormed Steel Rack Uprights Following Stomping During Rocking." Journal of Constructional Steel Research, 159: 189-197.

Maguire, J. R., Teh, L. H., Lee, C. L., Clifton, G. C., and Lim, J. P. B. 2018. “Three-dimensional simulation of the dynamic rocking response of a cold-formed steel pallet rack." In 2018 NZSEE Conference Papers.

McKenna, F. 2016. “OpenSees - Open System for Earthquake Engineering Simulation.”

Montuori, R., G. Gabbianelli, E. Nastri, and M. Simoncelli. 2019. "Rigid plastic analysis for the seismic performance evaluation of steel storage racks." Steel and Composite Structures, 32 (1): 1-19.

Petrone, F., P.S. Higgins, N.P. Bissonnette, and A.M. Kanvinde. 2016. "The Cross-Aisle Seismic Performance of Storage Rack Base Connections.” Journal of Constructional Steel Research, 122: 520-31.

Pollino, M. 2015. "Seismic Design for Enhanced Building Performance Using Rocking Steel Braced Frames.” Engineering Structures 83: 129-39.

Priestley, M. J. N., R. J. Evison, and A. J. Carr. 1978. "Seismic Response of Structures Free to Rock on Their Foundations.” Bulletin of the New Zealand National Society for Earthquake Engineering, 11 (3): 141-50.

Rack Manufacturers Institute. 2012. "Specification for the Design, Testing and Utilization of Industrial Steel Storage Racks, ANSI MH16.1-2012.” Standard. Charlotte, USA: RMI.

Standards New Zealand. 2004. "Structural Design Actions, Part 5: Earthquake Actions - New Zealand, NZS 1170.5:2004.” Standard. NZS.

Steele, T., and L. Wiebe. 2016. "Dynamic and Equivalent Static Procedures for Capacity Design of Controlled Rocking Steel Braced Frames.” Earthquake Engineering \& Structural Dynamics, 45 (14): 2349-69. 